\title{
Sero Status Disclosure and Condom use among Plwhas on Art in Assela Town Health Facilities, Oromiya Region
}

\section{Hailu Fekadu ${ }^{1 *}$, Mesfin Addisie ${ }^{2}$ and Habtamu Mellie ${ }^{3}$}

${ }^{1}$ Department of Public Health, Adama University, Asela, Ethiopia

${ }^{2}$ School of Public Health, Addis Ababa University, Addis Ababa Ethiopia

${ }^{3}$ Department of Public Health, Debre Markos University, Debre Markos, Ethiopia

\begin{abstract}
Background: HIV Status disclosure and sexual behavior of PLWHAS is vital for HIV prevention efforts and the couple's health in the context of accelerated highly active antiretroviral therapy. Therefore it is essential to see serostatus disclosure and sexual behavior of PLWHAs who are taking ART as this has implication for prevention of HIV epidemic.
\end{abstract}

Objective: To assess sero status disclosure and condom use among PLWHAs who are on ART in Assela town health facilities, Arsi Zone, Oromiya Region.

Methodology: institution based cross sectional study was conducted using both quantitative and qualitative methods from February to April 2013 among 324 PLWHAs who are taking ART from Assela town health institutions. Structured and pretested questionnaire was used for data collection of qualitative part and semi-structured questionnaire was used for qualitative part.

Result: More than half of the participants 167 (51.5\%) were females. The majority 264 (81.5\%) were married. Over all $94.1 \%$ of the respondents had disclosed their HIV positive result to their regular partner. Knowledge of partners' sero status, prior discussion about HIV, type of relationship with partner, living in the same home and duration of HIV test were determinants of sero status disclosure. The proportion of consistent condom use in this study was $(60.8 \%)$ and the main reason reported for not using condom were partner's refusal (37.4\%). Prior discussion about HIV test, duration since ART started, history of condom use and sex of respondent were found to be determinants of consistent condom use.

Conclusion: Although the magnitude of HIV positive status disclosure to regular partner found in this study was encouraging, lack of disclosure by a minority resulted in a limited ability to engage in preventive behaviors. Therefore HIV prevention programs and organizations working on HIV should further enhance disclosure and condom use using different mechanisms like mass health education and face to face counseling.

Keywords: Sero status disclosure; Sexual behavior; Condom use; PLWHA on ART

\section{Background}

It has been three decades since HIV started its spread across the globe with a devastating impact on populations and economies of countries and regions, some more than others. UNAIDS estimates that there were 34 million people living with HIV at the end of 2011 [1]. Sub-Saharan Africa continues to bear an inordinate share of the global HIV burden [2]. Ethiopia is one of the sub-Saharan countries worst affected by the HIV/AIDS pandemic. According to the Ministry of Health of Ethiopia report published in 2011, approximately 1.1 million people were living with HIV, In the same year, the national adult HIV prevalence was estimated to be $1.5 \%$ and a total of 34,936 people were newly infected with HIV, of whom 24,967 (71\%) were adults [3,4]. In the study area the number of PLWHAs on follow up during the study period were 8,376 among these 2,767 of them were taking ART from Assela town health facilities.

Disclosing HIV sero-status has paramount significances like to have safe sexual intercourse using condom, for caring/supporting of PLWHA in taking medication or nutritional modifications as needed. Despite its importance, only (58.2\% and 97\%) PLWHA in Barbados and Nigeria were disclosing their results [5,6]. In different parts of Ethiopia like kemisie, Jimma university hospital and Hawasa University referral Hospital, the respective disclosure status were $94.5 \%, 90.8 \%$ and $85.7 \%$ respectively [7-9] With regarding condom use, about little over half of,
North Shewa Zone (62\%) and Addis Ababa, Ethiopia (63.1\%) PLWHA were reporting as using condom consistently $[10,11]$.

Even though PLWHAs are given knowledge about safer sexual behavior during the ART (Anti-Retroviral Therapy) clinic sessions, there is growing evidence suggests that people on ART are increasingly becoming sexually active and many of them are involved in sexual activity with partners who are HIV negative. Moreover failure to disclose HIV positive status could lead to unsafe sexual practice, which in-turn increases risk of infecting sexual partner, couples re-infection with new strains and HIV transmission to the child. Thus, the aim of this study was to assess the magnitude of HIV status disclosure and condom use, and its associated factors among HIV positive ART attendants in Assela town health institution, Oromiya region. The result of the study would use for policy makers and other organizations working on HIV/

*Corresponding author: Hailu Fekadu, Department of Public Health, Adama University, Asela, Ethiopia, Tel: +251-911-71-76-08; E-mail: hailufekadu18@yahoo.com

Received November 16, 2014; Accepted December 28, 2014; Published January 05, 2014

Citation: Fekadu H, Addisie M, Mellie H (2014) Sero Status Disclosure and Condom use among Plwhas on Art in Assela Town Health Facilities, Oromiya Region. AIDS Clin Res 6: 414. doi:10.4172/2155-6113.1000414

Copyright: ( 2014 Fekadu $\mathrm{H}$, et al. This is an open-access article distributed unde the terms of the Creative Commons Attribution License, which permits unrestricted use, distribution, and reproduction in any medium, provided the original author and source are credited. 
AIDS to plan ways for further sero status disclosure and for further promoting use of condom among PLWHAs.

The objective of this study was to assess the degree of HIV status disclosure and condom use and to identify associated factors among PLWHA who are taking ART in Assela town health facilities, Arsi Zone, Oromiya Region.

\section{Methodology}

\section{Study area and period}

The study was conducted from February to April, 2013 in Assela town health facilities, which is found in Arsi Zone, Oromiya Region located 175 kilometers east of Addis Ababa, the capital city of Ethiopia. Assela is the capital town of Arsi zone with a total population of 74,268 with sex distribution of $49.73 \%$ males and $50.27 \%$ females. The town has one zonal hospital and two health center. One of the health centers and the hospital provides currently Anti-Retroviral Therapy service. Like other part of the Oromiya HIV/AIDS is the major health problem in Assela town with huge social and economic consequences which has followed the epidemic.

\section{Study design and population}

Facility based cross-sectional study was conducted using quantitative research approach supplemented by qualitative methods.

The study population was PLWHA attending Anti-Retroviral Therapy clinic and had tested positive at least six months prior to the study and started ART, had been sexually active in the past three months and were 18 years of age or above

Inclusion criteria: ALL PLWHAs who were registered in AntiRetroviral Therapy clinic, took ART for more than six months, sexually active and his/her age is above or equal to 18 years

\section{Exclusion criteria}

PLWHAs who were mentally or critically ill, sexually inactive during data collection time and not willing to participate in the study were excluded from study.

Sample size (n) required for this study was calculated by using single population proportion (p); by taking the proportion of sero status disclosure from metu town which was $69 \%, 5 \%$ level of significance and 5\% margin of error (precision) the calculated sample size was 294, and after adding 10\% non-response rate the final sample size was 324 PLWHAs on ART. For qualitative study a total of 14 (10 PLWHAs and 4 key informants for the in-depth interview) were selected using purposive sampling technique.

\section{Measurements}

The dependent variable for this study were HIV positive status disclosure to a partner and consistent condom use

The independent variables includes socio-demographic characteristics (age, sex, income, education, religion, marital status, occupation, place of residence), relationship factors (having single or multiple partners, duration of relationship, regular or casual partner, quality of relationship, discussion about HIV with partner, fear of partner's reaction, HIV status of partner), illness related factors (duration of test result and duration of ART start), active substance and alcohol use. Quantitative data were collected by pre-tasted questionnaire, which was adapted, from different studies [7,12]. Semi structured questioner for In-depth interview were used in qualitative study.
The quality of data was controlled starting from the time of questionnaires preparations. First the questionnaire which was prepared by English was translated into Afaan Oromo. To insure the consistency of the tool it was translated back to English. Training was given for supervisors and data collectors on the purpose of study and procedures of data collection for 2 days prior to study. After completing the training, trainees were conducted a pre-test at non study health facility.

The collected data were entered into computer for analysis by using Statistical packages: Epi-info version 3.5.1. After the entrance and completeness of all data, cleaning was done. Finally, the data were exported to SPSS version 17 for further analysis. Both the descriptive and Bivariate /multivariate logistic regression analysis were performed. Crude logistic regression were used to see relationship between one independent variable with outcome at time and adjust logistic regression were used to see relationship between many independent variables with outcome variable after controlling confounding factors. The result was presented using appropriate frequencies, proportions, odds ratio and $95 \%$ confidence interval. A P-value $<0.05$ was considered statistically significant. Correlation between the independent variable was run to see their correlation coefficient $(r)$ and not include two variables having correlation coefficient greater than $0.6(r>0.6)$ to avoid multicollinearity problem.

\section{Qualitative study}

To enrich the information obtained by quantitative study, in-depth interview of one to one discussion was held for the qualitative part. The in-depth interviews were conducted by the principal investigator in a private room and each interview lasted for 30-40 minutes. Each interview was tape recorded and notes were taken during each in-depth and key informant interview after that content analysis was used. Then the qualitative finding was triangulated with the quantitative part.

Ethical clearance letter was obtained from Research and ethics Committee (REC) of school of public health, Addis Ababa University. A written consent was obtained from Assela Hospital and Health center. Additionally an informed written consent was obtained from each respondent after providing sufficient information on the purpose of study.

\section{Results}

\section{Socio-demographic characteristic of study participants}

A total of $324 \mathrm{HIV}$ positive individuals who were taking ART were interviewed, yielding a response rate of $100 \%$. More than half 167 $(51.5 \%)$ were females. The mean age of the respondent was 36.33 years $( \pm 7.79)$ and the majority of them $264(81.5 \%)$ were married. More than two third 233 (71.9\%) of them were followers of Orthodox Christianity. About 207 (63.9\%) of the study participants were Oromo ethnic group. Two hundred fifty two (77.8\%) lived in urban area. Regarding to educational status, 119 (36.7\%) were between grade 5 to 8 . The median monthly income of study subjects were 500 Ethiopian birr (shown in Table 1). At the time of study, the mean duration of receiving ART was $39.8 \pm 23.8$ months.

\section{Sexual behavior of respondents before tested positive}

For one hundred fifty six (48.1\%) of the respondents, the test was done more than 49 months ago for 101 (31.2\%), the test was done 25-48 months ago, and for the rest, the test was done within 24 months before this survey. The majority $288(88.9 \%)$ of them were never use condom before tested HIV. One hundred fifty seven (48.5\%) of them had history of multiple sexual partner before tested positive (shown in Table 2). 
Citation: Fekadu H, Addisie M, Mellie H (2014) Sero Status Disclosure and Condom use among Plwhas on Art in Assela Town Health Facilities, Oromiya Region. J AIDS Clin Res 6: 414. doi:10.4172/2155-6113.1000414

Page 3 of 7

\begin{tabular}{|c|c|c|c|}
\hline Variable & Male freq(\%) & Female freq(\%) & Total freq (\%) \\
\hline \multicolumn{4}{|l|}{ Age category } \\
\hline $18-24$ & $1(0.6 \%)$ & $14(8.4 \%)$ & $15(4.6 \%)$ \\
\hline $25-34$ & $25(15.8 \%)$ & $90(54.2 \%)$ & $115(35.5 \%)$ \\
\hline $35-44$ & $96(60.8 \%)$ & $55(33.1 \%)$ & $151(46.6 \%)$ \\
\hline$\geq 45$ & $36(22.8 \%)$ & $7(4.2 \%)$ & $43(13.3 \%)$ \\
\hline \multicolumn{4}{|l|}{ Current marital status } \\
\hline Single & $14(8.9 \%)$ & $22(13.3 \%)$ & $36(11.1 \%)$ \\
\hline Married & $134(84.8 \%)$ & $130(78.3 \%)$ & $264(81.5 \%)$ \\
\hline Divorced & $6(3.8 \%)$ & $7(4.2 \%)$ & $13(4.0 \%)$ \\
\hline Widowed & $4(2.5 \%)$ & $7(4.2 \%)$ & $11(3.4 \%)$ \\
\hline \multicolumn{4}{|l|}{ Religion } \\
\hline Orthodox & $103(65.2 \%)$ & $130(78.3 \%)$ & $233(71.9 \%)$ \\
\hline Muslim & $40(25.3 \%)$ & $20(12 \%)$ & $60(18.5 \%)$ \\
\hline Protestant & $15(9.5 \%)$ & $16(9.6 \%)$ & $31(9.6 \%)$ \\
\hline \multicolumn{4}{|l|}{ Ethnic group } \\
\hline Oromo & $113(71.5 \%)$ & $94(56.6 \%)$ & $207(63.9 \%)$ \\
\hline Amhara & $39(24.7 \%)$ & $62(37.3 \%)$ & $101(31.2 \%)$ \\
\hline Others* & $6(3.7 \%)$ & $10(6 \%)$ & $16(4.9 \%)$ \\
\hline \multicolumn{4}{|l|}{ Place of residence } \\
\hline Urban & $115(72.8 \%)$ & $137(82.5 \%)$ & $252(77.8 \%)$ \\
\hline Rural & $43(27,2 \%)$ & $29(17.5 \%)$ & $72(22.2 \%)$ \\
\hline \multicolumn{4}{|l|}{ Education } \\
\hline Unable to write \& read & $7(4.4 \%)$ & $28(16.9 \%)$ & $35(10.8 \%)$ \\
\hline Grade 1-4 & $27(17.1 \%)$ & $20(12 \%)$ & $47(14.5 \%)$ \\
\hline Grade $5-8$ & $51(32.3 \%)$ & $68(41 \%)$ & $119(36.7 \%)$ \\
\hline Grade $9-12$ & $45(28.5 \%)$ & $43(25.9 \%)$ & $88(27.2 \%)$ \\
\hline College\& above & $28(17.7 \%)$ & $7(4.2 \%)$ & $35(10.2 \%)$ \\
\hline \multicolumn{4}{|l|}{ Occupation } \\
\hline Government employee & $41(26.1 \%)$ & $12(7.2 \%)$ & $53(16.4 \%)$ \\
\hline private employee & $33(21 \%)$ & $20(12 \%)$ & $53(16.4 \%)$ \\
\hline House wife & $(0 \%)$ & $50(30.1 \%)$ & $50(15.4 \%)$ \\
\hline Daily laborer & $26(16.6 \%)$ & $48(28.9 \%)$ & $74(22.8 \%)$ \\
\hline Merchant & $19(12.1 \%)$ & $31(18.1 \%)$ & $50(15.4 \%)$ \\
\hline Farmer & $33(21 \%)$ & $4(2.4 \%)$ & $37(11.4 \%)$ \\
\hline Others & $5(3.2 \%)$ & $2(1.2 \%)$ & $7(2.2 \%)$ \\
\hline \multicolumn{4}{|l|}{ Average monthly income } \\
\hline No income/l don't know & $1(0.6 \%)$ & $36(21.7 \%)$ & $37(11.4 \%)$ \\
\hline$\leq 500$ & $59(37.3 \%)$ & $79(47.6 \%)$ & $138(42.6 \%)$ \\
\hline $501-1000$ & $50(31.6 \%)$ & $29(17.5 \%)$ & $79(24.4 \%)$ \\
\hline $1001-1500$ & $16(10.1 \%)$ & $2(7.2 \%)$ & $28(8.6 \%)$ \\
\hline$>1500$ & $32(20.3 \%)$ & $10(6 \%)$ & $42(13 \%)$ \\
\hline
\end{tabular}

In the in-depth interview most respondents had reported history of sexual intercourse with multiple sexual partners with inconsistent condom use. One of HIV positive man who is on ART from Assela town explains his past sexual behavior as:

"Before I became ill, I had been a member of Ethiopian military and I had a bad behavior, I engaged in sexual intercourse with multiple sexual Partners like bar ladies. I used condom sometimes with those ladies but not at all time."

\section{HIV status disclosure}

Among the 324 participants 311 (96.0\%) of the respondents disclosed their HIV positive status at least to one person $(96.2 \%$ men Vs $95.8 \%$ women); while 305 (94.1\%) of respondents disclosed their result to their current regular partner. Among respondents who had casual sexual partner only $13(34.2 \%)$ were disclosed their result to any of these partners.

Among respondents who were disclosed their sero-status to their regular partner 30 (19.1\%) of women and 14 (9.5\%) of men had unprotected sex with their partner before telling their result to their partner. Concerning sero status disclosure time 212 (69.5\%) were told their result immediately and the rest 93 (30.6\%) were delayed. (As showed in Table 3).

Among respondents who participate in the in-depth interview the majority of them were reported that they were disclosed their result to their partner. A 40 years female respondent explains her experience of disclosure as follows:

"I disclosed my result to my husband and to my children because my husband and I were tested at the same time in the same health facility. Now, we are taking ART drug together from the same health institution"

\subsection{Barriers of participants for sero - status disclosure}

Among participants who did not disclose their test results to their partner the commonest reasons mentioned were, fear of separation / divorce (26.3\%), fear of labeling as bad person (26.3\%), and the other reasons were depicted in Table 4.

Qualitative informants raised many reasons for hiding their sero status from their partners, of these fear of separation or divorce is prominent one. A 24 years male respondent stated that:

"I did not tell her my HIV-positive results because she was tested before me and she knew that her result is negative. Beside this we quarrel

\begin{tabular}{|l|c|c|}
\hline Characteristic & Frequency & Percentage(\%) \\
\hline The types of HIV counseling they used to be tested & & \\
\hline VCT & 153 & 47.2 \\
\hline PIHCT & 171 & 52.8 \\
\hline The duration since tested positive (months) & & \\
\hline$\leq 24$ & 67 & 20.7 \\
\hline $25-48$ & 101 & 31.2 \\
\hline$\geq 49$ & 156 & 48.1 \\
\hline Marital status by the time they know & & \\
\hline their HIV status & & 79.3 \\
\hline Married & 257 & 11.7 \\
\hline Single & 38 & 3.7 \\
\hline Divorced & 12 & 5.2 \\
\hline Widowed & 17 & \\
\hline Number of sexual partners before tested HIV & & \\
\hline Single & 167 & 51.5 \\
\hline Multiple & 157 & 48.5 \\
\hline Knowledge of partners sero status before test & & \\
\hline Yes & 44 & 13.6 \\
\hline No & 280 & 86.4 \\
\hline History of condom use before testing HIV & & \\
\hline Yes & 288 & 88.9 \\
\hline No & & \\
\hline Condom use pattern before testing HIV & 288 & \\
\hline Consistently used & & \\
\hline Inconsistently used & & \\
\hline Not used at all & & \\
\hline Table & & \\
\hline
\end{tabular}

Table 2: sexual behavior of study participants before tested positive, Assela, Ars zone 2013. 
Citation: Fekadu H, Addisie M, Mellie H (2014) Sero Status Disclosure and Condom use among Plwhas on Art in Assela Town Health Facilities, Oromiya Region. J AIDS Clin Res 6: 414. doi:10.4172/2155-6113.1000414

Page 4 of 7

\begin{tabular}{|l|c|c|c|}
\hline Variables & Male Freq(\%) & $\begin{array}{c}\text { Female } \\
\text { Freq(\%) }\end{array}$ & $\begin{array}{c}\text { Total } \\
\text { Freq(\%) }\end{array}$ \\
\hline Disclosed to any one (N=324) & & & \\
\hline Yes & $152(96.2 \%)$ & $159(95.8 \%)$ & $311(96.0 \%)$ \\
\hline No & $6(3.8 \%)$ & $7(4.2 \%)$ & $13(4.0 \%)$ \\
\hline $\begin{array}{l}\text { Disclosed to main sexual } \\
\text { partner(N=324) }\end{array}$ & & & \\
\hline Yes & $148(93.7 \%)$ & $157(94.6 \%)$ & $305(94.1 \%)$ \\
\hline No & $10(6.3 \%)$ & $9(5.4 \%)$ & $19(5.9 \%)$ \\
\hline $\begin{array}{l}\text { Disclosed to casual sexual } \\
\text { partner(n=38) }\end{array}$ & & & \\
\hline Yes & $9(37.5 \%)$ & $4(28.6 \%)$ & $13(34.2 \%)$ \\
\hline No & $15(62.5 \%)$ & $10(71.4 \%)$ & $25(65.5 \%)$ \\
\hline $\begin{array}{l}\text { Delayed disclosure to main } \\
\text { partner(n=305) }\end{array}$ & & & \\
\hline Yes & $44(29.7 \%)$ & $49(31.2 \%)$ & $93(30.6 \%)$ \\
\hline No & $104(70.3 \%)$ & $108(68.8 \%)$ & $212(69.5 \%)$ \\
\hline Sex before disclosure(n=305) & & & \\
\hline Yes & $14(9.5 \%)$ & $30(19.1 \%)$ & $44(14.4 \%)$ \\
\hline No & $134(90.5 \%)$ & $127(80.9 \%)$ & $261(85.6 \%)$ \\
\hline
\end{tabular}

Table 3: Magnitude of Sero status disclosure among PLWHAs who are taking ART, Assela , Arsi zone, 2012/13.

\begin{tabular}{|l|c|c|c|}
\hline Reason for non disclosure & $\begin{array}{c}\text { Male } \\
\text { Freq(\%) }\end{array}$ & $\begin{array}{c}\text { Female } \\
\text { Freq(\%) }\end{array}$ & $\begin{array}{c}\text { Total } \\
\text { Freq(\%) }\end{array}$ \\
\hline He/She might leave me & $2(20 \%)$ & $3(33.3 \%)$ & $5(26.3 \%)$ \\
\hline $\begin{array}{l}\text { He/She might be afraid of } \\
\text { catching HIV from me }\end{array}$ & $1(10.0 \%)$ & $0(0 \%)$ & $1(5.3 \%)$ \\
\hline He/She might think I am a bad person & $2(20 \%)$ & $3(33.3 \%)$ & $5(26.3 \%)$ \\
\hline He/She is too young to handle it & $1(10.0 \%)$ & $0(0 \%)$ & $1(5.3 \%)$ \\
\hline The person may tell others & $3(30.0 \%)$ & $2(22.2 \%)$ & $5(26.3)$ \\
\hline He/ She might think I am unfaithful & $1(10.0 \%)$ & $1(11.1 \%)$ & $2(10.5 \%)$ \\
\hline
\end{tabular}

Table 4: Barriers of respondents for HIV status disclosing among PLWHAs, Assela, Arsi zone 2012/13.

so many times therefore if I tell my result to her now, she will leave me and will marry to another person"

\section{Sexual behavior and condom use among PLWHAs}

Among sexually active respondents 305 (94.1\%) had single partner and 19 (5.9\%) had multiple partners since started ART. In the occasion of their last sex, $233(71.9 \%)$ of the respondents used condom and the rest did not used. Concerning condom use since HIV diagnosed 197 $(60.8 \%)$ of the respondents were using condom consistently whereas the remaining 127 (39.2\%) were either using condom inconsistently or did not use it at all. Two Hundred eighty six (88.3\%) of those individuals had sexual practice with regular partner and 38 (11.7\%) of them with none regular partner. Among those who had sex with non-regular partner, the majority $25(65.8 \%)$ of them were without disclosure of their sero status. (Table 5)

From the in-depth interview one female respondent who was in sero discordant relation explains her sexual behavior as;

"My husband is HIV negative we were tested before marriage and at that time, I want to separate from him, but he didn't do so, why because he loves me. We were counseled about condom use but we did not use condom always as a result we have two children now. Fortunately, both my children and my husband is HIV negative".

\section{Factors associated with disclosure}

As sown in table 6. From all the variables, living with partner in the same home, relationship with partner, Knowledge of partner's HIV status and prior discussion were determinants of sero status disclosure.

Respondents those who had duration of test greater than two years were found to have eight fold increased odds of disclosure compared to those who had less than two year (AOR:8.4; 95\% CI: 1.21,57.7). Whereas, respondents those were not living in the same home with their partner were $99 \%$ less likely to disclose their HIV status to a partner in comparison with those living together (AOR, 0.01; 95\% CI: $0.001,0.27)$. The other predictor of HIV status disclosure was partner's relationship. Participants those were lived in disagreement relation with their partners were (99\%) less likely to disclose their HIV status than their counterparts $(\mathrm{AOR}=0.01 ; 95 \% \mathrm{CI}: 0.001,0.2)$. In addition participants who did not discuss about HIV and testing with their partners were $93 \%$ less likely to disclose their HIV status than their counterparts $(\mathrm{AOR}=0.07 ; 95 \% \mathrm{CI}: 0.01,0.98)$ (Table 6$)$.

\section{Factors associated with condom use}

As depicted in Table 7, factors that are independently associated with consistent condom use were explored using multivariate analysis. In the multiple logistic regression model, Sex of respondent, prior discussion about HIV testing and duration since ART start were

\begin{tabular}{|c|c|c|}
\hline Characteristic & Frequency & Percentage (\%) \\
\hline \multicolumn{3}{|c|}{ Duration since ART start in month } \\
\hline$\leq 24$ & 109 & 33.6 \\
\hline $25-48$ & 109 & 33.6 \\
\hline$\geq 49$ & 106 & 32.7 \\
\hline \multicolumn{3}{|c|}{ Health condition since started ART } \\
\hline Improved & 341 & 96.6 \\
\hline No change & 9 & 2.8 \\
\hline Deteriorated & 1 & .3 \\
\hline \multicolumn{3}{|c|}{ Sexual desire since ART } \\
\hline Improved & 41 & 12.7 \\
\hline Normal & 186 & 57.4 \\
\hline Decreased & 97 & 29.9 \\
\hline \multicolumn{3}{|c|}{ Sexual intercourse in the last 3 month } \\
\hline Yes & 311 & 96 \\
\hline No & 13 & 4 \\
\hline \multicolumn{3}{|c|}{ No of partners since ART } \\
\hline Single & 305 & 94.1 \\
\hline Multiple & 19 & 5.9 \\
\hline \multicolumn{3}{|c|}{ Condom use in the last sexual intercourse } \\
\hline Yes & 233 & 71.9 \\
\hline No & 91 & 28.1 \\
\hline \multicolumn{3}{|c|}{ Condom use since HIV positive diagnosis } \\
\hline Consistently used & 197 & 60.8 \\
\hline In consistently used & 96 & 29.6 \\
\hline Not used at all & 31 & 9.6 \\
\hline \multicolumn{3}{|c|}{ Sexual intercourse with non regular partner } \\
\hline Yes & 38 & 11.7 \\
\hline No & 286 & 88.3 \\
\hline \multicolumn{3}{|c|}{ Sero status disclosure to non regular partner } \\
\hline Yes & 13 & 34.2 \\
\hline No & 25 & 65.8 \\
\hline \multicolumn{3}{|c|}{ Condom use with non regular partner } \\
\hline Yes & 16 & 42.1 \\
\hline No & 22 & 57.9 \\
\hline
\end{tabular}

Table 5: Sexual behavior and condom use among PLWHAs on ART, Assela Arsi zone 2012/13. 
Citation: Fekadu H, Addisie M, Mellie H (2014) Sero Status Disclosure and Condom use among Plwhas on Art in Assela Town Health Facilities, Oromiya Region. J AIDS Clin Res 6: 414. doi:10.4172/2155-6113.1000414

Page 5 of 7

\begin{tabular}{|c|c|c|c|c|}
\hline Variables & Disclosed N(\%) & Not disclosed N(\%) & Crude $\mathrm{OR}(95 \% \mathrm{Cl})$ & Adjusted OR(95\% Cl) \\
\hline \multicolumn{5}{|l|}{ Marital status } \\
\hline Married & $260(85.2 \%)$ & $4(21.1 \%)$ & $21.7(6.9,68.3)$ * & $0.7(0.03,16.9)$ \\
\hline Unmarried & $45(14.5 \%)$ & $15(78.9 \%)$ & 1.0 & 1.0 \\
\hline \multicolumn{5}{|c|}{ Live in the same home } \\
\hline Yes & $284(99 \%)$ & $3(1 \%)$ & 1.0 & 1.0 \\
\hline No & $21(56.8 \%)$ & $16(43.2 \%)$ & $0.02(.004, .05)^{*}$ & $0.01(0.001,0.27)^{\star *}$ \\
\hline \multicolumn{5}{|c|}{ Duration of test in year } \\
\hline$=<2$ & $57(85 \%)$ & $10(14.9 \%)$ & 1.0 & 1.0 \\
\hline$>2$ & $248(96.49 \%)$ & $9(3.5 \%)$ & $4.8(1.9,12.4)$ * & $8.4(1.2,57.7)^{* *}$ \\
\hline \multicolumn{5}{|c|}{ Relation with partner before test } \\
\hline Peaceful & $209(99.5 \%)$ & $1(.5 \%)$ & 1.0 & 1.0 \\
\hline With disagreement & $96(84.2 \%)$ & $18(15.8 \%)$ & $0.03(0.003,0.2)^{*}$ & $0.01(0.001,0.2)^{\star *}$ \\
\hline \multicolumn{5}{|c|}{ Discussion before test (HIV) } \\
\hline Yes & $286(99.3 \%)$ & $2(.7 \%)$ & 1.0 & 1.0 \\
\hline No & $19(52.8 \%)$ & $17(47.2 \%)$ & $0.01(0.002,0.04) *$ & $0.07(0.01,0.98)^{\star *}$ \\
\hline \multicolumn{5}{|c|}{ Know partner's HIV status } \\
\hline Yes & $288(99.7 \%)$ & $1(.3 \%)$ & 1.0 & 1.0 \\
\hline No & $17(48.6 \%)$ & $18(51.4 \%)$ & $0.003(0.001,0.03)^{\star}$ & $0.003(0.001,0.1)^{\star *}$ \\
\hline \multicolumn{5}{|c|}{ Duration since ART started } \\
\hline$=<24$ & $96(88.1 \%)$ & $13(11.9 \%)$ & 1.0 & 1.0 \\
\hline $25-48$ & $105(96.3 \%)$ & $4(3.7 \%)$ & $3.6(1.1,11.3)$ & $2.3(0.09,55.2)$ \\
\hline$=>49$ & $104(98.1 \%)$ & $2(1.9 \%)$ & $7.1(1.6,32.0)^{*}$ & $1.3(0.05,33)$ \\
\hline \multicolumn{5}{|c|}{ No of partner since started ART } \\
\hline Single & $291(95.4 \%)$ & $14(4.6 \%)$ & $7.42(2.34,23.52)$ * & $0.9(0.08,46)$ \\
\hline Multiple & $14(73.7 \%)$ & $5(26.3 \%)$ & 1.0 & 1.0 \\
\hline \multicolumn{5}{|c|}{ Use condom regularly } \\
\hline Yes & 195(99\%) & $2(1 \%)$ & $15.5(3.5,68.3)^{*}$ & $0.01(0.00,1.5)$ \\
\hline No & $107(86.3 \%)$ & $17(13.7 \%)$ & 1.0 & 1.0 \\
\hline \multicolumn{5}{|l|}{ Type of partner } \\
\hline Non regular & $31(81.6 \%)$ & $7(18.4 \%)$ & 1.0 & 1.0 \\
\hline Regular & $274(95.8 \%)$ & $12(4.2 \%)$ & $5.16(1.89,14.06)$ * & $0.2(0.004,6.7)$ \\
\hline
\end{tabular}

*Statistically significant at $p$-value $<0.05$

** Significant after adjusted for other variables

Table 6: Factors associated with HIV status disclosure among HIV positive ART users Assela, Arsi, zone 2012/13.

\begin{tabular}{|c|c|c|c|c|}
\hline \multirow[t]{2}{*}{ Variables } & \multicolumn{2}{|c|}{ Condom use } & \multirow{2}{*}{ (COR 95\%CI) } & \multirow{2}{*}{ (AOR $95 \% \mathrm{Cl}$ ) } \\
\hline & Consistent & inconsistent/ not used at all & & \\
\hline \multicolumn{5}{|l|}{ Sex } \\
\hline Male & $110(69.6 \%)$ & $87(52.4 \%)$ & $2.1(1.3,3.28)$ & $2.0(1.2,3.64) * *$ \\
\hline Female & $48(30.4 \%)$ & $79(47.6 \%)$ & 1.0 & 1.0 \\
\hline \multicolumn{5}{|c|}{ Duration since ART started } \\
\hline$\leq 24$ & $96(88.1 \%)$ & $13(11.9 \%)$ & 1.0 & 1.0 \\
\hline $25-48$ & $105(96.3 \%)$ & $4(3.7 \%)$ & $2.2(1.3,3.8)$ & $1.8(0.88,3.1)$ \\
\hline$\geq 49$ & $104(98.1 \%)$ & $2(1.9 \%)$ & $2.3(1.4,4.0)$ & $2.2(1.17,4.03)^{\star *}$ \\
\hline \multicolumn{5}{|c|}{ Reside in the same house } \\
\hline Yes & $182(63.4 \%)$ & $105(35.6 \%)$ & $2.6(1.3,5.73)$ & $0.69(0.2,2.3)$ \\
\hline No & $15(40.5 \%)$ & $22(59.5 \%)$ & 1.0 & 1.0 \\
\hline \multicolumn{5}{|c|}{ Discussion about HIV } \\
\hline Yes & $187(64.9 \%)$ & $101(35.1 \%)$ & $3.46(1.1,10.90)$ & $2.9(1.03,8.2)^{\star *}$ \\
\hline No & $10(27.8 \%)$ & $26(72.2 \%)$ & 1.0 & 1.0 \\
\hline \multicolumn{5}{|c|}{ Knowledge of partners HIV status } \\
\hline Yes & $185(64 \%)$ & $104(36 \%)$ & $3.5(1.68,7.35)$ & $0.62(0.2,1.9)$ \\
\hline No & $12(34.3 \%)$ & $23(65.7 \%)$ & 1.0 & 1.0 \\
\hline \multicolumn{5}{|c|}{ Disclosed HIV status to partner } \\
\hline Yes & $195(63.9 \%)$ & $110(36.1 \%)$ & $15(3.4,66.4)$ & $6(0.75,48.4)$ \\
\hline
\end{tabular}

*Statistically significant at $\mathrm{p}$-value $<0.05$

** Significant after adjusted for other variables

Table 7: Factors associated with condom use among PLWHA who are taking ART inAssela , Arsi zone, 2012/13. 
found to be determinants of consistent condom use (Table 7). Being male is two times more likely used condom consistently than female respondents ( $\mathrm{AOR}=2.0 ; 95 \% \mathrm{CI}: 1.2,3.64)$. And the odds of consistent condom use among the respondents who discussed about HIV with their partner was almost three times higher than respondents who did not discussed about HIV (AOR=2.9; 95\% CI: 1.1 to 8.2). Participants who were taking ART at least for forty nine months were more likely used condom compared to other group ( $\mathrm{AOR}=2.17 ; 95 \% \mathrm{CI}: 1.17,4.03)$.

\section{Discussion}

This facility based cross sectional study was intended to provide insight into sero status disclosure patterns and sexual behavior among PLWHAs who are taking ART treatment from Assela town health institution. The results of the study raise several critical public health concerns that have key implications for interventions aimed at reducing HIV infection. The results show that sero status disclosure and sexual behavior among sero-concordant and sero-discordant partners was mainly influenced by individual level, socio demographic and socio economic factors such as marital status, duration of test, discussion about HIV with partner, type of relationship, number of partners, Knowledge of partner's HIV status, and type of partners.

The general level of disclosure in this study was high (96\%) told to at least one person, this result was comparable to a study done in Nigeria which was (97\%) [5]. But it is higher than the study done in kemisie, Jimma university hospital and Hawasa University referral hospital which were $(94.5 \%),(90.8 \%)$ and $(85.7 \%)$ respectively [7-9]. Still much higher than in Barbados about, (58.2\%) of those interviewed had disclosed their HIV status to significant others [6]. This difference may be due to variations in study setting, study time, study population and mass media educations about the issue

The current finding of not disclosing HIV sero-status to the regular sexual partner (5.9\%) was nearly comparable with a study conducted in kemisie district, Ethiopia (6.9\%) [9] and but lower than the study conducted in Nigeria (10\%) [5]. The possible reason for discrepancy with Nigerian study might be due to variations in health policy or mass media promotions in disclosure and or regular health education given during follow up in ART clinic.

In agreement with other studies, the proportion of disclosure to casual sex partners in this study was much lower than disclosure to regular sexual partners (34.2\% vs. $94.1 \%)$. Possible explanation for this is that those patients on ART who disclosed their HIV status were due to a sense of responsibility to their main partners and less concern for casual partners' health. Although the magnitude of sero status disclosure found in this study is encouraging, significant proportion (30.5\%) of the disclosures were delayed, which is higher than a study done in Jimma University hospital (14.1\%) [13]. This might be individuals differ in decision making when and how to disclose their result. As a result these individuals had at least one sexual contact with their untold sexual partner before disclosure which raises the possibility of transmission risk if condom were not used.

Concerning barriers of sero status disclosure the most common reason mentioned by the participants were fear of abandonment, fear of labeling as bad person and fear of breach of confidentiality. This was in line with other studies which was done in Jimma University hospital, kemise, and metu town $[8,13]$.

Regarding outcome of disclosure $72.5 \%$ of the respondents were reported supportive reaction from their partner. This result was similar to the studies conducted in Mettu and Jimma town $[7,13]$. This is also supported by qualitative study. But higher than a study conducted in Hawasa University Referral hospital which was (40.7\%) [9]. In this study negative out comes like violence and breaking in sexual relationship following disclosure were only (4\%). This is comparable with a study reported in sub-Saharan Africa (5\%) [2]. But it was much lower than that reported in South Africa and Hawasa University Referal hospital $(14.6 \%)$ and $(14.3 \%)$ respectively $[9,14]$. This variation may be due to variations of study populations, health institution specific promotions of disclosure and stigma and discriminations following disclosure.

In this study, it was observed that being living in the same home, having duration of test greater than two years, having peaceful relation with partner, Prior discussion about HIV test, and knowledge of partner's HIV status, were among factors associated with disclosure of HIV status to main sexual partner. And this is consistent with studies elsewhere in our country $[7,8]$.

The current finding revealed as HIV sero-positive participants who had duration of test greater than two years were eight times more likely disclosed their status to their sexual. This implies that sero status disclosure increases over time as people adjust to their results [12]. Similar to other study participants who were living with disagreement relation with their partner were less likely to disclose their status than their counter parts. This might be due to having disagreement relations leading to less discussion about HIV and HIV testing which may later make difficult to disclose their sero status.

The current study revealed that the proportion of consistent condom use since they knew their HIV status was (60.8\%). This was comparable with a research done in North shewa Zone and Addis Ababa public hospitals which was (62\%) and (63.1\%) respectively $[10,11]$. Unprotected sex and inconsistent use of condom among PLWHA increases the risk of transmission of resistant HIV strains and re-infection with new strains, unwanted pregnancy and mother to child transmission of HIV. But higher than study done in Kampala Uganda which was (45.5\%). The variation with Kampala Uganda study might be due to discrepancies in study area, study time promotion and accessibility of condom.

The finding of proportion of condom use at last sex (71.9\%) in this study was in line with a study in Addis Ababa public hospitals (70.4\%) and North shewa health facility $(73.1 \%)$ respectively $[10,11,15]$. But higher than a study done in Mombassa (44\%) [15]. The similarity between the two findings might be due to similarity in study design and study setting and health policy of the country and the discrepancy with Mombassa study could be partially explained by variation in the study setting health policy and cultural differences of the study population.

Important finding of this research is that the proportion of consistent condom use among disclosed respondents were high $(63.5 \%$ vs. $10.5 \%$ ) compared to those did not disclose their HIV positive status. In addition the odds of consistent condom use among disclosed partners were nearly five times higher than their counter parts and this finding was supported by a prior study [7]. Finding from qualitative respondents were also support this idea. This show that facilitating HIV status disclosure is a key point for consistent condom use and it helps in reducing HIV transmission.

The current finding of having multiple partners (5.9\%) was in parallel with a study done in South Africa (5.6\%). But lower than a study done in Addis Ababa public hospitals (10\%) and much lower than a study done in North shewa zone $(42.7 \%)[10,11]$.The variation with the last finding may possibly attributable by differences in study populations which are living a capital city of Ethiopia in case of Addis 
Citation: Fekadu H, Addisie M, Mellie H (2014) Sero Status Disclosure and Condom use among Plwhas on Art in Assela Town Health Facilities, Oromiya Region. J AIDS Clin Res 6: 414. doi:10.4172/2155-6113.1000414

Ababa and similarly North shewa zone is found near Addis Ababa thus these areas easily get different channels of mass media which gives health education about HIV and its prevention methods.

In contrary with other study the commonest reason mentioned for not using condom were partner's refusal (37.4\%) followed by condom take away the pleasure of sex (24.2\%). In other way the reason mentioned in the study conducted in North shewa zone Health facility were both partners being infected with HIV (41.2\%) followed by partners refusal (16.2\%) this finding is inconsistent with other studies done in Ethiopia [7,10,11].The difference may be explained as people may be give different reasons for their bad behaviors. So efforts should be strengthen on sexual health intervention focusing on the couple than the individual and monitoring of client's attitudes and practice on their follow up period.

\section{Conclusions}

Large level of respondents were disclosed their sero status to their partner. One of the implications of this high disclosure rate is the likelihood of a high rate of partner support and having clear communication about preventive interventions. Prior discussion about HIV tes, living in the same home with partner, having peaceful relation with partner, duration of test and knowledge of partners' status were significantly associated with sero status disclosure.

Significant proportions of inconsistent condom use were reported among the respondents. Prior discussion about HIV TEST, duration since ART started, history of condom use and sex of respondent were found to be determinants of consistent condom use. Based on the finding ART scale-up programs should further enhance disclosure of sero-status and condom use by behavioral change health education and condom promotion using different Medias.

\section{Acknowledgements}

Our deepest gratitude goes to Addis Ababa University School of public health for financial support. Lastly our thanks go to the data collectors and all research participants who took place in the study.

\section{References}

1. UNAIDS (2011) Global HIVIAIDS response Epidemic update and health sector progress towards Universal Access, Progress Report.

2. WHO (2010) HIVIAIDS Health profile Sub-Saharan Africa.

3. $M O H(2011)$ HIVIAIDS Health profile The Federal HIVIAIDS Prevention and Control Office Ethiopia.

4. CSA (2012) The Ethiopia Demographic and Health Survey (EDHS).

5. Nanyonga R (2010) sexual behaviour among people living with HIV on antiretroviral therapy at mpigi health center $1 \mathrm{v}$, central uganda.
6. Igwegbe Ao (2010) Rate and correlates of HIV serostatus disclosure among HIV positive pregnant women in Nnewi southeastern Nigeria. Journal of Medicine and Medical Science 1: 296-301.

7. Kebede Deribe, Kifle Woldemichael, Mekitie Wondafrash, Amaha Haile Alemayehu Amberbir ( 2008) Disclosure experience and associated factors among HIV positive men and women clinical service users in southwest Ethiopia. BMC Public Health 8: 81.

8. Mohammed Seid, Belaynew Wasie, Mengesha Admassu (2012) Disclosure of HIV Positive Result to a Sexual Partner among Adult Clinical Service Users in Kemissie District, Northeast Ethiopia. Afr J Reprod Health 16: 97-104

9. Taye G, Dereje H, Endrias M (2010) HIV positive status disclosure to sexual partner among women attending ART clinic at Hawassa University Referral Hospital, SNNPR, Ethiopia. Ethiop J Health Dev 24: 9-14.

10. Yadeta D, GerbabaM, Abdo B, Gail D (2011) Risky Sexual Practices and Related Factors among HIV-Positive ART Attendees in Addis Ababa Public Hospitals, Ethiopia. BMC Public Health 11:422.

11. Asefa N ( 2013) sexual behavior and determinants of condom use among hiv/ aids patients who are on art in north shewa health. J Phys Pharm Adv 3: 247260 .

12. Deribe K, Woldemichael K, Njau BJ, Yakob B, Biadgilign S, et al. ( 2010) Gender differences regarding barriers and motivators of HIV status disclosure among HIV-positive service. Journal of Social Aspects of HIVIAIDS Research Alliance 7

13. Kebede Deribe Kassaye, Wassie Lingerh, Yismaw Dejene (2005) Determinants and outcomes of disclosing HIV-sero positive status to sexual partners among women in Mettu and Gore towns, Illubabor Zone southwest Ethiopia. Ethiop.J.Health Dev 19: 126-131.

14. Motlatso Mlambo, Karl Peltzer (2011) HIV Sero-status Disclosure and Sexua Behaviour among HIV Positive Patients who are on Antiretroviral Treatment (ART) in Mpumalanga, South Africa. J Hum Ecol 35: 29-41.

15. Horizon W (2007) Sexual Risk Behaviors of HIV-positive Persons Receiving ART in Mombasa, Kenya: Longitudinal Study Findings. 